\title{
LAS CERTEZAS DEL INTERÉS SUPERIOR DEL MENOR EN EL CONTEXTO DE LOS DERECHOS DE LA INFANCIA
}

\author{
THE CERTAINTIES OF THE BEST INTEREST OF THE CHILD \\ IN THE CONTEXT OF CHILDREN'S RIGHTS
}

\author{
Ma OLGA SÁNCHEZ MARTÍNEZ \\ Universidad de Cantabria
}

Recibido: 30/06/2017

Aceptado: 03/08/2017

\begin{abstract}
Resumen: La situación de dependencia y vulnerabilidad de las personas en la etapa de su infancia ha constituido siempre un motivo de reflexión desde muy diversas perspectivas, desde las que el beneficio del menor ha estado de una u otra forma presente. Pero el beneficio del menor adquiere una nueva dimensión con el reconocimiento de los derechos de la infancia, bajo el concepto del interés superior del menor. En este contexto, el interés superior del menor se concreta en un derecho sustantivo, un principio interpretativo, dirigido a arbitrar conflictos entre distintos intereses, y una norma procedimental. Sobre la base de esta triple dimensión se construyen muchas certezas que permiten evitar la arbitrariedad y limitar la discrecionalidad en las decisiones en torno a un concepto jurídico, cuya indeterminación es a menudo enfatizada.
\end{abstract}

Palabras clave: derechos de la infancia, el interés superior del menor, certeza, discrecionalidad.

Abstract: The situation of dependence and vulnerability of people in the stage of their childhood has always been a motive of reflection from very diverse perspectives, from which the benefit of the minor has been present in one way or another. But the benefit of the minor acquires a new dimension with the recognition of the rights of the infancy, under the concept of the best interest of the child. In this context, the best interest of the minor is embodied in a substantive right, an interpretive principle, aimed at arbitrating conflicts between different interests, and a procedural standard rule. On the basis of this triple dimension, many certainties are constructed that allow to avoid arbitrariness and limit discretion in the decisions concerning a legal concept, whose indetermination is often emphasized.

Keywords: rights of children, the best interests of the child, legal certainty, legal discretion

SUMARIO: 1. INTRODUCCIÓN. 2. LOS DEBERES DE CUIDADO Y PROTECCIÓN DE LA INFANCIA EN LA FILOSOFÍA DE LA ILUSTRACIÓN Y DEL LIBERALISMO POLÍTICO. 3. LA LIBERTAD RESTRINGIDA DE LA INFANCIA: EL PATERNALISMO JUSTIFICADO EN SU BENEFICIO. 4. EL INTERÉS SUPERIOR DE UNA INFANCIA CON DERECHOS. 5. LAS CERTEZAS DEL INTERÉS SUPERIOR DEL MENOR. 5.1. Un derecho a proteger y promover derechos. 5.2. Un principio dirigido a resolver conflictos entre derechos, bienes e intereses. 5. 2.1. El interés superior del menor árbitro en los conflictos entre distintos derechos del menor. 5. 2. 2. El interés superior del menor frente a intereses de terceros. 5.3. Una norma de procedimiento: motivación, flexibilidad, estabilidad y celeridad. 6. A MODO DE CONCLUSIÓN. 7. BIBLIOGRAFÍA. 


\section{INTRODUCCIÓN}

El paradójico universo de los derecho humanos ha constituido el centro de una concepción de justicia basada en la libertad, la igualdad y la autonomía de los miembros de una sociedad incluidos en su ámbito de acción: de los naturalmente incluidos, de los legítimamente incluidos o de los legalmente incluidos. Pero también del dominio y la autoridad sobre los excluidos. Los derechos humanos se han hecho fuertes, y han hecho fuertes a sus titulares, frente a quienes carecían de ellos. Pero han adquirido también una gran fuerza para atraer hacia sí a grupos excluidos por distintas y "poderosas" razones que, presentadas en muchas ocasiones como naturales e irreversibles, han ido perdiendo virtualidad y mostrado la posibilidad y capacidad de muchos sujetos para ejercer autónomamente derechos que les habían sido en otros momentos negados. Se pone así de manifiesto que aquellas razones no eran tan naturales ni tan irreversibles, sino que más bien provenían de razones culturales, relativas y cambiantes. Dentro de la amplia categoría de sujetos que han sido excluidos del ámbito de los derechos humanos, los menores presentan ciertas peculiaridades.

Establecer una categoría general de niños/as, infancia o menores, constitutiva de una regulación uniforme para todos los sujetos y situaciones comprendidas en ella, resulta de una extraordinaria complejidad, ya que la infancia presenta unas peculiaridades propias que no afectan a otras circunstancias personales, que actúan como factor de diferenciación de los individuos. Al respecto, dos características especiales de los menores, en relación a su posición jurídica, han de ser destacadas. En primer lugar, la situación de dependencia de los menores durante un periodo de sus vidas es universal y radical, debido a su falta de capacidad y autonomía. Sin embargo, tal circunstancia no es permanente, varía por el mero transcurso del tiempo, relativizándose a lo largo de su crecimiento. De ahí que al tratar los derechos de los menores se aborden desde el presente y se proyecten hacia el futuro, que se configuren derechos específicos de protección y derechos genéricos de autonomía y que sean afrontados desde una perspectiva gradual, admitiendo diferencias en su ejercicio según edades o grados de madurez.

En segundo lugar, el ámbito en el que se desarrolla la vida del menor, al menos en la primera infancia, es primordialmente privado, en el ámbito de la intimidad familiar, siendo naturalmente los padres y las madres sobre quienes primero recae la responsabilidad de protección, cuidado y bienestar de los niños y niñas. Una responsabilidad que si no es adecuadamente ejercida puede llevar a la desprotección del menor, tanto mayor cuanto lo sea su grado de dependencia. Los niños serían, en este sentido, doblemente vulnerables, por un lado, son dependientes y, por otro lado, esta dependencia se desenvuelve en un entorno de difícil acceso a la intervención pública.

Estas características propias de los menores marcarán la evolución de su tratamiento jurídico, acorde con la visión que la sociedad tiene de ellos, desde su condición de sometidos al poder de unos progenitores que les deben naturalmente protección y cuidado, a la exigencia jurídica del deber de dicha protección y cuidado, para alcanzar finalmente el reconocimiento de los menores como titulares de derechos 
específicos de protección y cuidado, además de otros derechos que configuran su identidad y desarrollo de su personalidad.

Reconocidos los derechos de la infancia, su garantía y efectividad reposa, en gran medida, sobre el concepto del interés superior del menor, un concepto jurídico indeterminado, cuyas certezas serán analizadas a través de su triple configuración: como un derecho a proteger y promover derechos, un principio dirigido a resolver conflictos entre derechos, bienes e intereses diversos y una norma de procedimiento.

\section{LOS DEBERES DE CUIDADO Y PROTECCIÓN DE LA INFANCIA EN LA FILOSOFÍA DE LA ILUSTRACIÓN Y DEL LIBERALISMO POLÍTICO}

La dependencia y privacidad en que se desenvuelve la vida del menor, en un ámbito familiar tradicionalmente regido por criterios de autoridad y desigualdad entre sus miembros, ha producido que la posición jurídica del menor haya estado centrada durante mucho tiempo, antes que en sus derechos, en los poderes y deberes hacia ellos de aquellas personas adultas con quienes conviven y de quienes dependen, especialmente de sus progenitores, y en relación con las necesidades más básicas que impone la naturaleza para la supervivencia, no con las voluntades y deseos del menor ${ }^{1}$. Las necesidades de los menores encuentran su satisfacción, desde esta perspectiva, a través de los deberes de cuidado que tienen hacia ellos sus progenitores y no de ningún derecho propio.

La exclusión del menor de la titularidad de los derechos humanos trae su causa en los propios fundamentos que propiciaron su nacimiento. Los derechos humanos surgen con la finalidad de proteger un ámbito de autonomía del individuo frente al poder estatal, como si de una relación entre dos soberanos se tratase. Se parte entonces de una concepción de los individuos como libres e iguales, con independencia y capacidad de razón como atributos esenciales del sujeto soberano, de los que se presuponía carecían los menores ${ }^{2}$.

Las propias características naturales de los menores le llevaron a Kant a sostener que no dándose en ellos las condiciones de libertad -como hombre-, de igualdad - como súbdito- y de independencia - como ciudadano-, tampoco procedía su reconocimiento como sujeto de derecho. La libertad deslinda el tipo de relación que procede de un padre con sus hijos, paternalista, de la de un gobierno con sus súbditos, patriótica, la única que cabe pensar para "hombres capaces de tener derechos". El paternalismo propio de los padres hacia los hijos trasladado al ámbito político

$1 \quad$ Cfr. E. GARZÓN VALDÉS, "Desde la $<$ modesta propuesta $>$ de J. Swift hasta las $<$ casas de engorde $>$. Algunas consideraciones acerca de los derechos de los niños", DOXA, n. 15-16, 1994, p. 736.

2 Cfr. L. HUNT, La invención de los derechos humanos, trad. J. Beltrán Ferrer, Barcelona, 2009, p. 16. Puede verse también, L. L. HIERRO, “Autonomía y derechos humanos: ¿para qué se inventaron los derechos humanos?", en ID. (Coord.), Autonomía individual frente a autonomía colectiva. Derechos en conflicto, Madrid, 2014, pp. 28-31. 
convertiría al gobierno en el "mayor despotismo imaginable", tratando a los súbditos como niños, incapaces de distinguir lo que es "verdaderamente" beneficioso o perjudicial. La igualdad general de los súbditos, en cuanto al sometimiento a la ley, le resulta perfectamente compatible con la "máxima desigualdad" en sus posesiones o derechos en general, como sucede en el caso de que uno ha de obedecer y el otro mandar ("como el niño a los padres o la mujer al marido") 3 . En cuanto a la independencia necesaria para ser ciudadano, exige además de la cualidad natural (no ser niño ni mujer), ser su propio señor, sustentando en tener propiedad, habilidad, oficio, arte o ciencia que le mantenga. Así pues, el derecho de libertad corresponde a los miembros de la comunidad en cuanto hombres adultos capaces de tener derechos, en claro contraste con los niños ${ }^{4}$. Ahora bien, la carencia de aquellas cualidades necesarias para ser sujetos de derecho en los menores no les impedirá ser protegidos por las leyes como miembros de la comunidad, pero no como ciudadanos, sino como "coprotegidos" 5 .

Pero el menor no es solo un niño, es también un aspirante a ser adulto, a ser soberano, y ha de ser preparado para ello. Locke así lo puso de manifiesto en su crítica a Filmer, quien precisamente tomó como modelo de la relación de los súbditos con el gobierno, la del padre con el hijo, justificando la autoridad absoluta del padre sobre los hijos y la del monarca sobre el pueblo, acudiendo a la disposición divina y al derecho natural derivado del hecho de haberlos engendrado. Un derecho natural de dominio, pero también de cuidado, ya que la ley de la naturaleza obliga al padre a hacer todo cuanto pueda para preservar a su familia. Ahora bien, el gobierno sobre la familia depende de la voluntad del padre y no de las leyes civiles, ni de la voluntad de los hijos. No existe, señala, "nación que permita a los hijos ninguna acción ni remedio cuando son injustamente gobernados", siendo esto una cuestión de bien público ${ }^{6}$. Ningún derecho, por tanto, asiste a los hijos frente a un padre que no atienda a sus deberes naturales de cuidado y protección.

Locke pondrá en jaque a ese "extraño fantasma dominante, conocido con el nombre de paternidad", que pueda derivar del solo hecho de la generación un poder absoluto e ilimitado sobre la prole ${ }^{7}$. La infancia, por carecer el menor de entendimiento suficiente para regirse por sí mismo, es un estado imperfecto del ser humano. Una situación de debilidad natural que impide al menor cuidarse solo. Ahora bien, de esta debilidad no se deriva que carezca de libertad natural. El hijo es libre naturalmente, en tanto participa de la libertad de un padre que dirige sus acciones y su voluntad hasta que pueda ejercerlas por sí mismo. Tal dirección no es una limitación

3 I. KANT, "En torno al tópico: tal vez eso sea correcto en teoría, pero no sirve para la práctica”, en ID., Teoría y práctica, trad. M. F. Pérez López y R. Rodríguez Aramayo, Madrid, 1986, p. 29.

$4 \quad$ Ibidem, p. 28.

Ibidem, pp. 32-34.

$6 \quad$ R. FILMER, "El Patriarca", en La polémica Filmer-Locke sobre la obediencia política, trad. C. Gutiérrez de Gambra, Madrid, 1996, p. 53.

7 J. LOCKE, "Primer Ensayo sobre el gobierno civill, en ID., Dos Ensayos sobre el gobierno civil, trad. F. Giménez Gracia, Madrid, 1991, p. 54. 
a aquella libertad natural, mucho menos su abolición o restricción, sino su preservación, una condición de su posibilidad, la dirección de un agente libre y dotado de razón hacia su "propio interés", hacia la "máxima utilidad para ellos y la sociedad".

El poder paternal es, en realidad, el deber de los progenitores sobre sus hijos, que redunda en "provecho" de los hijos, para gobernarlos "por su bien" 9 . No hay, para Locke, un derecho natural de los progenitores sobre sus hijos, pero tampoco un derecho de los hijos, sino un privilegio a ser cuidados, alimentados e instruidos por sus padres y en la medida de que así lo hagan. Un privilegio que se corresponde con los deberes, no sólo del padre, sino compartido con la madre y que es atribuido igualmente a un padre natural que a uno adoptivo. Un deber que no se limita a la mera subsistencia, sino que se extiende a las comodidades y conveniencias de la vida, que puedan proporcionarle los padres según sus posibilidades. Si bien para Locke los padres no ostentan un derecho, ni un poder sobre los hijos, sino que están sujetos a un deber, seguimos estando en el ámbito de la naturaleza; su deber es natural, sostenido por el amor y la ternura que la naturaleza ha puesto en los padres y que les mueve a cuidar de los hijos como a una parte de sí mismos ${ }^{10}$.

Por otro lado, Locke no contempla al menor propiamente, desde el presente como tal niño, sino proyectándolo hacia el futuro, como ciudadano burgués, y así lo muestra al tratar sobre los principios de la educación "dirigidos a un burgués a quien consideré como un pliego en blanco o como cera que se puede moldear y labrar según el gusto de cada cual" "1. El destino del niño, "su bien" y el bien público es convertirlo en hombre político.

La educación de los niños con vistas al diseño político estaba ya planteada en la República de Platón y será un elemento central de la filosofía política de Rousseau, en la que el contrato social quedaría incompleto sin la educación de Emilio, de un niño que "se vuelve más valioso al avanzar la edad" 12 . Un niño al que no se le enseñan derechos sino deberes, los deberes del hombre, hombres para la especie, para la sociedad y para el Estado. Un niño al que conceder más libertad verdadera implica limitar sus deseos, una libertad limitada por su debilidad; un niño que no debe saber lo que es obediencia cuando actúa ni lo que es dominio cuando se actúa por él; un niño de quien hay que hacer un hombre razonable sin razonar con él, porque carece de tal facultad; un niño a quien hay que proteger especialmente de sí mismo. Un paradójico aprendizaje de la libertad a través del sometimiento inconsciente hacia su educador, una propuesta de educación para la libertad que no parte de la libertad de quienes son educados ${ }^{13}$.

8 ID., "Segundo Ensayo sobre el gobierno civil", en Dos Ensayos sobre el gobierno civil, cit., pp. 244, 248-249.

$9 \quad$ Ibidem, pp. 252, 329.

$10 \quad$ Ibidem, pp. 131, 137.

11 J. LOCKE, Pensamientos sobre educación, trad. R. Lasaleta, Madrid, 1986, p. 275.

12 J. J. ROUSSEAU, J. J., Emilio o De la educación, trad. M. Armiño, Madrid, 1990, p. 50. Afirma que "no me encargaría de un niño enfermizo, siempre inútil a sí mismo y a los demás" (Ibidem, p. 58).

13 Ibidem, pp. 52, 79, 101, 107, 152, 451. 
Derechos y deberes naturales en relación a un menor cuyo máximo valor estará en convertirse en el futuro en un ciudadano. Todavía no se ha desplegado la idea de que el hijo es un sujeto valioso en sí mismo, no como futuro adulto, sino como niño y que ha de ser sujeto de derechos. Un hijo que es para sí mismo, ni para sus padres, ni para el Estado ${ }^{14}$. Un hijo que no es obra de quienes lo engendraron o lo criaron, como si fuera un objeto. Un menor que no es tampoco propiedad de nadie ${ }^{15}$. Si sólo se mantuviera un poder sobre él, el hijo sería algo "impersonal, neutro, anónimo", pero con el hijo comienza una existencia nueva y libre, es "ruptura y comienzo" en otro "yo" que no es "yo mismo"16.

Los deberes de los padres no han de ser ya naturales sino jurídicos para Stuart Mill, quien reclamará la intervención jurídica sobre la actuación de los padres en relación a los menores. Para Mill la familia constituida sobre bases justas será la verdadera escuela para las virtudes propias de la libertad. Aunque tal justicia estará centrada básicamente en la igualdad y libertad para los padres y madres, porque respecto a los hijos la familia será siempre escuela de obediencia y sumisión ${ }^{17}$. Ahora bien, si el Estado ha de respetar la libertad de cada uno en todo aquello que le concierne, debe intervenir en el ejercicio de todo poder que tengan conferido sobre los demás. Y siendo indudable la imposibilidad de que los menores ejerzan libertad alguna, y el poder que sobre ellos ejercen sus padres, hará un reproche a la ausencia de la intervención estatal cuando los hijos son desatendidos en el ámbito familiar. Es preciso reconocer que engendrar un hijo exige tener una seguridad fundada de poderle proporcionar alimento para su cuerpo e instrucción para su espíritu, tanto por el bien del vástago como de la sociedad y que si no se cumple tal obligación debería poder hacerlo cumplir el Estado ${ }^{18}$. El poder de los padres debería aparecer irremediablemente acompañado del deber exigible por el Estado.

Dos aspectos fundamentales aporta Stuart Mill en relación a los deberes de protección y cuidado hacia los menores. Primero, el cuidado y protección de los padres hacia los hijos no es una cuestión estrictamente privada sino que reclama la intervención del Estado, en caso de que los deberes hacia los hijos no sean cumplidos por los padres. En segundo lugar, que los deberes de los padres sobre los menores y, en su caso, la intervención del Estado está orientada al bien del menor, que es al mismo tiempo el de la sociedad. Ahondando más, ese bien está constituido no sólo por bienes materiales, sino también espirituales.

14 Cfr. S. AGACINSKI, Politica de sexos, trad. H. Subirats y M. Baiges, Madrid, 1998, pp. 108,110 .

15 E. LEVINAS, Totalidad e infinito. Ensayo sobre la exterioridad, trad. D. E. Guillot, Salamanca, 1987, p. 285

16 Ibidem, p. 281.

17 Cfr. J. S. MILL, La esclavitud femenina, trad. E. Pardo Bazán, Madrid, 2008, p. 182.

18 ID., Sobre la libertad, trad. P. de Azcárate, Madrid, 1990, pp. 192-194. 


\section{LA LIBERTAD RESTRINGIDA DE LA INFANCIA: EL PATERNA- LISMO JUSTIFICADO EN SU BENEFICIO}

Respecto a la libertad del menor, Mill también hará alguna aportación importante. Partiendo de la libertad como un valor casi absoluto, entendía que cada persona es la más interesada en su propio bienestar. Las limitaciones a la libertad sólo estarían justificadas cuando una persona decida colocarse en una situación de esclavitud o cuando pueda producir un daño a tercero. Sin embargo, esta amplia concepción de la libertad vale para aquellas personas que están en plenitud de facultades. La libertad para tomar decisiones, elegir un plan de vida, actuar como se desee, se garantiza impidiendo interferencias externas en la esfera propia de actuación. Pero esto será así siempre que se parta de un sujeto con capacidad de discernimiento y razonamiento, que sea capaz de proponerse un plan de vida y de procurarse los medios adecuados para materializarlo. El valor absoluto de la libertad procederá, por tanto, para quienes sean capaces de hacer elecciones racionales, de estar en condiciones de poder valorar las repercusiones de sus actuaciones presentes y futuras. En esta situación no se encuentran los menores, para quienes Mill prevé una excepción a la ausencia de interferencias externas como garantía de la libertad individual, porque los niños y jóvenes, deben ser protegidos, no sólo de daños exteriores, sino de sus propios actos ${ }^{19}$.

Protección de daños externos, protección de sí mismo restringiendo la libertad de quien no tiene capacidad para plantearse proyectos de vida propios, ni procurarse los medios de vida necesarios para alcanzarlos, para procurarle un bien que consiste tanto en cubrir necesidades materiales como espirituales. Sin duda, entre esos bienes espirituales estará la libertad restringida en el presente, pero proyectada hacia el futuro. El menor, aquejado de deficiencias en su conocimiento y voluntad es débil y vulnerable, susceptible por aquellas razones de estar sometido a riesgos y padecer daños de los que ha de ser protegido. Las limitaciones actuales de su libertad permitirían preservar su libertad, vendrían a compensar la carencia de facultades para su ejercicio ahora y hacerla fuerte en el futuro como adulto ${ }^{20}$. Tales restricciones se corresponderían con lo que Dworkin denomina un supuesto de paternalismo puro, en el que la clase de personas cuya libertad se restringe coincide con la clase de personas cuyo beneficio o interés se intenta promover, teniendo en cuenta que las deficiencias de la capacidad de los menores para la toma de decisiones son más o menos evidentes y también los perjuicios, en muchos casos, permanentes, a los que se verían sometidos dejándoles actuar por sí mismos ${ }^{21}$. La injerencia en la actuación de los menores, estaría justificada en su misma libertad, no resultando un obstáculo a la misma, sino una garantía de su consecución y preservación ${ }^{22}$.

19 Ibidem, p. 66.

20 Cfr. E. GARZÓN VALDÉS, “Es éticamente justificable el paternalismo jurídico?”, DOXA, no. 5, 1988, pp. 160-163.

21 Cfr. G. DWORKIN, "Paternalism”, en R. SARTORIUS (ed.), Paternalism, Minneapolis, 1993, pp. 19-34.

22 Cfr. J. GONZÁLEZ AMUCHASTEGUI, Autonomía, dignidad y ciudadanía. Una teoría de los derechos humanos, Valencia, 2004, pp. 373-416. Esto permitiría afirmar que la libertad de 
Las limitaciones a la libertad y la justificación de la intervención paternalista en beneficio de la propia libertad es analizada por Rawls tomando como ejemplo el caso de los menores, cuya libertad menos extensa a la libertad igual se deriva de rasgos naturales propios del ser humano. La justificación del paternalismo con respecto a ellos procede de algunas presunciones acerca de la posición original, en concreto de la racionalidad de protegerse contra las propias decisiones que puedan tomarse en circunstancias de racionalidad y voluntad deficiente y aceptar ciertas restricciones para evitar consecuencias perjudiciales. Circunstancias en las que sería racional también autorizar, e incluso exigir, a otros que actúen en beneficio de quienes padecen aquellas carencias. Ahora bien, justificando el paternalismo y la restricción de la libertad en la propia protección de quien ve limitadas sus libertades actuales, el paternalismo justo no puede interpretarse de modo que permita ataques a la integridad personal, a los objetivos y convicciones finales, o que impida desarrollar los poderes o satisfacer racionalmente los intereses a las personas en cuyo beneficio se actúa. En definitiva, la prioridad de la libertad conlleva que solo pueda restringirse en favor de la libertad en sí misma ${ }^{23}$.

El principio de igualdad vendría también en auxilio de la libertad para justificar el comportamiento paternalista en relación a la protección de los menores, en el sentido de que sus circunstancias particulares los coloca en una situación de desigualdad y desventaja respecto a los adultos. Medidas de desigualdad en favor de los menos aventajados que sólo compensarían aquella desigualdad inicial si la intervención tiene como finalidad obrar en beneficio del propio menor, ya que si no fuera así se ahondaría en la desigualdad que se trata de enmendar ${ }^{24}$.

Considerando justificada y necesaria la intervención sobre las actuaciones y decisiones de los menores en su beneficio, el primer contexto de intervención se produce, casi de forma natural, en el ámbito cooperativo de la familia, el más próximo y en el que se supone mejor se conoce lo que es beneficioso para el menor. Enfocar la atención sobre el menor -como persona vulnerable- y no sobre el adulto, permite entender que la relación entre padres e hijos, aún desigual, o precisamente por ser desigual, no se desenvuelva en un contexto de poder-deber, sino de saber-deber, saber lo que les beneficia, deber de protegerlos, procurándoles un bien ${ }^{25}$.

opción, las facultades de ejecución y renuncia no son constitutivas de los derechos, cfr. N. MacCORMICK, "Los derechos de los niños: una prueba de fuego para las teorías del derecho", en ID. Derecho legal y socialdemocracia. Ensayos sobre la filosofía jurídica y política, trad. L. M. González Soler, Madrid, 1982, pp. 129-137.

23 Cfr. J. RAWLS, Teoría de la Justicia, trad. M. D. González, Madrid, 1993, pp. 280-287.

24 La fuerza de la justicia, señala Rawls, se deriva de que todas las desigualdades se justifiquen para los menos aventajados, Ibidem, p. 286. Suponiendo que la menor libertad implica un beneficio para compensar la situación de desventaja, debería ser racionalmente aceptable por los ciudadanos afectados por la limitación (Ibidem, p. 287). Dworkin apela para justificar la limitación a la libertad del menor a una suerte de consentimiento orientado al futuro, es decir, a aquello que se supone los menores consentirían racionalmente al ser adulto. Cfr. G. DWORKIN, "Paternalism", cit., pp. 32-34.

${ }_{25}$ Cfr. V. CAMPS, "Paternalismo y bien común”, DOXA, n 5, 1988, pp. 195-202; cfr. M. ALEMANY, El paternalismo jurídico, Madrid, 2006, pp. 398-413. 
Como bien había advertido Mill, el bienestar del menor no es una cuestión meramente privada o familiar, sino pública y colectiva, de ahí que reclame la intervención del Estado y del Derecho. Bien es cierto que Mill solo contemplaba la intervención del Estado en un contexto conflictivo, cuando la familia no atendiera sus deberes con respecto a los hijos. Sin embargo, siendo conscientes de que los déficits de libertad y capacidad no solo provienen de características personales o de impedimentos jurídicos sino de circunstancias sociales, económicas o culturales, contribuir a socavar dichos impedimentos se convierte en una necesidad para preservar la libertad y promover la igualdad de las personas menores. En este sentido, la intervención del Estado no solo procede en un contexto conflictivo sino en el cooperativo de las familias, apoyándolas para cumplir sus cometidos de protección y cuidado de los menores.

\section{EL INTERÉS SUPERIOR DE UNA INFANCIA CON DERECHOS}

Aunque podríamos decir que la intervención sobre la voluntad y decisión de los menores, es decir, la restricción a su libertad es natural, debido a su incapacidad, lo cierto es que actualmente dicha intervención solo puede enmarcarse en la evolución de la concepción que la sociedad tiene sobre la infancia y la propia evolución de los derechos humanos. Una evolución que ha transcurrido desde la configuración de la minoría de edad como una situación de dependencia y sumisión que justificó el deber de protección y asistencia de los adultos con quienes conviven, hasta la consideración del menor como una persona titular de derechos específicos de protección y cuidado y derechos fundamentales, de cuya efectividad son responsables sus padres, la sociedad y los poderes públicos. El niño es un sujeto pleno de derechos, un ciudadano aunque en desarrollo, cuya protección incluye el fomento y respeto de su gradual autonomía y la participación en todos los ámbitos de la vida ${ }^{26}$.

Los textos generales de derechos humanos han ido reconociendo derechos a los niños, como el derecho de cuidado, protección y asistencia especiales, el derecho a tener un nombre y una nacionalidad, han recibido menciones expresas en materia de educación y salud y prohibiciones, también expresas, en materia de discriminación ${ }^{27}$. Pero no será hasta la Declaración de los Derechos del Niño de 1959, cuando se producirá el reconocimiento, en el plano internacional de los derechos fundamentales del niño. Y será también en este instrumento cuando ligado a los derechos fundamentales del menor aparezca la mención a su interés superior. En concreto, su segundo principio señala que el interés superior del niño ha de ser la consideración fundamental a atender al promulgarse leyes, con el fin de que el niño pueda gozar de una protección especial, para que pueda desarrollarse física, mental, moral, espiritual y

26 L. L. HIERRO SÁNCHEZ-PESCADOR, "El niño y los derechos humanos", en I. CAMPOY CERVERA (ed.), Los derechos de los niños: perspectivas sociales, politicas, jurídicas y filosóficas, Madrid, 2007, p. 27.

27 Véase artículos 25.2 y 26 de la Declaración Universal de Derechos Humanos, artículos 23. 1 y 24 de Pacto Internacional de Derechos Civiles y Políticos o los artículos 10, 12 y 13 del Pacto Internacional de Derechos Económicos, Sociales y Culturales. 
socialmente en condiciones de libertad y dignidad ${ }^{28}$. En la Convención Internacional para la Eliminación de todas las Formas de Discriminación contra la Mujer de 1979, existen dos previsiones sobre la discriminación de las mujeres en el ámbito familiar que apelan al interés superior de los hijos. En concreto, en el artículo 5. b se señala el deber de los Estados parte de adoptar medidas encaminadas al reconocimiento de la responsabilidad común de hombres y mujeres en la educación y desarrollo de los hijos, considerando que el interés de los hijos constituirá la consideración primordial en todos los casos. El artículo 16.1 b. reitera la consideración primordial del interés de los hijos en el ejercicio de los derechos y responsabilidades de ambos progenitores, con independencia del estado civil. Será, finalmente, la Convención Internacional de Derechos del Niño de 1989 el instrumento internacional comprensivo de la consideración jurídica del niño como titular de derechos humanos, tanto de derechos civiles y políticos, como de derechos sociales, económicos y culturales, como de derechos específicos de los menores justificados en su vulnerabilidad y, por tanto, en la necesidad de una protección especial.

En estas coordenadas es preciso enmarcar el artículo 3. 1 de la Convención que expresamente dice: "en todas las medidas concernientes a los niños que tomen las instituciones públicas o privadas de bienestar social, los tribunales, las autoridades administrativas o los órganos legislativos, una consideración primordial a que se atenderá será el interés superior del niño". Interés superior que se reiterará en la Convención en relación a algunos casos, que se constituyen también en derechos específicos de los menores como concreción de su interés superior, como la no separación del niño de sus padres contra su voluntad, en caso de separación mantener contacto con ellos, la preocupación fundamental en las responsabilidades de padres y madres en la crianza y desarrollo de los menores o la primordial consideración de su interés superior en la adopción ${ }^{29}$.

Con respecto a la legislación española, la Constitución en su artículo 39 configura la interacción entre el sector público y privado en la protección y garantías del derecho del menor, estableciendo el deber de los padres de prestar asistencia de todo

28 Sobre la evolución del reconocimiento y protección de los derechos del niño puede verse: L. M CALVO GARCÍA, "La protección del menor y sus derechos", en Derechos y Libertades, n'. 1, 1993, pp. 177-199; I. CAMPOY CERVERA, "Notas sobre la evolución en el reconocimiento y la protección internacional de los derechos de los Niños", Derechos y Libertades, nº. 6, 1998, pp. 279-327; P. TRINIDAD NÚÑEZ, "La evolución en la protección de la vulnerabilidad por el derecho internacional de los derechos humanos", Revista Española de Relaciones Internacionales, $\mathrm{n}^{\circ}$. 4, 2012, pp. 125-142.

29 En el artículo 9, establece el deber de los Estados de velar para que los niños no sean separados de sus padres contra su voluntad salvo que sea necesario en "interés superior del niño", así como que en caso de separación pueda mantener contacto regular con ambos, salvo si es contrario a su "interés superior". El artículo 20 lo hace extensivo a su medio familiar. El artículo 37 establece como regla que la privación de libertad del niño implica la separación de los adultos, "a menos que ello se considere contrario al interés superior del niño". El artículo 18 establece la responsabilidad primordial de ambos padres o de los representantes legales de la crianza y desarrollo del niño, siendo su preocupación fundamental el "interés superior del niño". El artículo 21, relativo a la adopción señala que el Estado cuidará de que el interés superior del niño sea "la consideración primordial". 
orden a sus hijos y a los poderes públicos el deber de asegurar su protección integral, en el marco previsto por los acuerdos internacionales que velan por sus derechos. La ratificación de la Convención Internacional de Derechos del Niño el 30 de noviembre de 1990 marcará un proceso de modificación de la normativa española en materia de menores, en consonancia con la nueva visión del menor que impone la Convención, centrada en sus derechos y en un mayor protagonismo y participación del mismo en la vida social. Dentro de este proceso de renovación normativa es destacable la Ley 21/1987, de 11 de noviembre, que permitió agilizar los procesos de protección del menor, introdujo nuevas instituciones de protección, ajustó la adopción a un proceso de plena integración familiar y generalizó el interés superior del menor como principio inspirador de todas las actuaciones relacionadas con él. Será la Ley Orgánica 1/1996, de 15 de enero, de Protección Jurídica del Menor -modificada en parte por Ley 26/2015, de 28 de julio, de modificación del sistema de protección a la infancia y a la adolescencia, y en concreto el artículo 2 referido al interés del menorla norma general que recoja las transformaciones propias del status social del menor que, construido sobre los derechos humanos de la infancia, intentará dar efectividad al reconocimiento pleno de la titularidad de sus derechos y a su capacidad progresiva para ejercerlos. La Exposición de Motivos de la Ley clarifica la concepción de los derechos del menor, en relación a las medidas protectoras que la misma contiene. Y así señala que la Ley es un reflejo de la consideración de las personas menores de edad como "sujetos activos, participativos y creativos, con capacidad de modificar su propio medio personal y social; de participar en la búsqueda y satisfacción de sus necesidades y en la satisfacción de las necesidades de los demás”.

En sintonía con esta nueva perspectiva de la infancia en términos de derechos, el bien o interés del menor ha sido sometido a un proceso de transformación. El interés del menor será un elemento esencial a efectos de justificar la intervención sobre su persona y sus actuaciones, estando dicho interés conformado por el desarrollo de su libertad, autonomía y sus derechos ${ }^{30}$. Partiendo del menor como un sujeto pleno de derechos, que la intervención de los adultos o los poderes públicos en las distintas facetas de su vida procure su bien o interés, está directamente relacionado con una eficaz garantía de sus derechos. En el contexto de los derechos humanos, por tanto, el interés del menor se configura como un elemento fundamental para justificar, y en la medida en que dicho interés sea susceptible de ser satisfecho, la intervención de sus progenitores, cuidadores o los poderes públicos. A tal fin, se ha convertido en el criterio fundamental para dotar de entidad y realidad jurídica a algunas instituciones jurídicas como la patria potestad, la adopción, el acogimiento o la guarda y custodia; configurador de algunos derechos como el derecho de visita o el derecho a ser informado y oído o el derecho de participación, y es también un modulador de algunos derechos fundamentales como el derecho a la educación, la salud, la libertad religiosa o el derecho al honor, la intimidad y la propia imagen ${ }^{31}$.

$30 \quad$ El interés del menor es la proyección al menor de la protección de los derechos fundamentales, cfr. E. ROCA, Familia y cambio social (De la “casa” a la persona), Madrid, 1999, p. 220.

31 Cfr. F. RIVERO HERNÁNDEZ, El interés del menor, Madrid, 2000, pp. 76-80. 
El interés del menor es el motor y el límite a la intervención, tanto de los adultos con quienes convivan, como de las instituciones privadas y públicas, en los derechos del menor. Un límite a la discrecionalidad, una orientación de sus actuaciones que garantiza que la intervención no conculcará sus derechos. Si quisiéramos calificar dicha intervención como paternalista, sería un paternalismo alejado del autoritarismo tradicionalmente ejercido sobre los menores, un paternalismo renovado que no deriva del poder de los padres, ni siquiera de sus derechos, o de las instituciones del Estado, sino de los derechos del menor. Un límite que encuentra su concreción en la autonomía progresiva del menor y en su derecho de participación en todos los asuntos que le afecten ${ }^{32}$. El interés del menor se erige en una garantía a la protección efectiva de los derechos del menor. Puede hablarse de un derecho específico de los menores dirigido a proteger sus derechos.

\section{LAS CERTEZAS DEL INTERÉS SUPERIOR DEL MENOR}

El interés del menor deviene pues en un derecho del menor y un principio fundamentador de toda intervención privada y pública sobre los distintos aspectos de la vida de los menores y, por lo tanto, atinente a toda normativa y decisiones a ellos referidos. Un interés que ha de contextualizarse en el ámbito de los derechos del menor y es en este contexto donde se han de encontrar las referencias que permitan concretar en qué consiste en cada caso el interés de los menores ${ }^{33}$.

El interés superior ha sido descrito como un concepto "fácil de pensar, pero complicado de aplicar" ${ }^{34}$. Se ha pretendido acentuar su carácter indeterminado, su vaguedad, su sometimiento casi intrínseco a múltiples interpretaciones y, en consecuencia, se ha resaltado el daño que puede producir a la seguridad jurídica. Incluso se ha señalado que puede resultar, al menos en ocasiones, pernicioso para el propio menor. Se le ha calificado como un concepto "esencialmente controvertido" "35, cuya dificultad de determinar deriva de la imposibilidad de conocer todas las opciones posibles que permite su aplicación, los resultados de cada opción, las probabilidades de cada resultado o el valor atribuido a estos resultados. Si a ello se le quiere añadir la idea de que es inevitable que el juez al decidir sobre él tenga en cuenta preferencias puramente subjetivas y, más aún, la injusticia de que, bajo tales circunstancias de

32 Cfr. M. CILLERO BRUÑOL, "El interés superior del niño en el marco de la Convención Internacional sobre los derechos del niño", Justicia y Derechos del Niño, $\mathrm{n}^{\circ} .1$, 1999, pp. 55-56.

33 Un estudio en profundidad sobre las diversas técnicas de concreción del interés del menor pueden verse en la tesis doctoral de F. S. CAMPAÑA, Interés superior del menor: técnicas de reducción de la discrecionalidad abusiva, Salamanca,2013 (https://gredos.usal.es/jspui/bitstream/10366/124216/1/DDP_Sim\%C3\%B3nCampa\%C3\%B1a_Farith_Tesis.pdf).

34 S. TAMAYO HAYA, "La custodia compartida como alternativa legal", Revista Crítica de Derecho Inmobiliario, no. 700, 2007, p. 670; ID., "El interés del menor como criterio de atribución de la custodia", Revista de derecho de familia: Doctrina, Jurisprudencia, Legislación, $\mathrm{n}^{\mathrm{o}}$. 41, pp. 35-79.

35 Dicha calificación proviene de nuestro Tribunal Supremo, en su Sentencia 835/2013, de 6 de febrero de 2014, Fundamento de Derecho Quinto. 3. 
incertidumbre, supondría priorizarlo sobre otros intereses más fácilmente determinables se ha podido concluir que, en ocasiones, sería más justo y práctico privarlo de relevancia, en favor de aquellos otros intereses u optar claramente por ellos ${ }^{36}$.

Ahora bien, el hecho de que un concepto pueda generar controversia, o que no exista un criterio unánime sobre cual sea el interés del menor en un caso concreto, sobre las distintas opciones para satisfacerlo, sobre el resultado que se obtendrá o sobre cuál sea el valor que se atribuya dichas opciones ${ }^{37}$, no implica que pueda ser controvertible "esencialmente" en todos los casos, que no existan criterios objetivos para concretarlo ni, mucho menos, que pueda convertirse en un concepto prescindible $^{38}$. Sobre este último extremo es preciso señalar que no existe incertidumbre ninguna, el interés del menor ha de valorarse con carácter preferente en cualquier decisión privada o pública sobre menores.

Más allá de esta certeza, conviene recordar con Hart que la indeterminación no es algo ajeno al derecho, sino el resultado del intento de aprehender en una norma general y abstracta la heterogeneidad de las relaciones humanas; una consecuencia de la condición humana de quienes lo crean, lo aplican y de las relaciones humanas que regula. Procede de la propia incapacidad humana para anticiparse a todos los posibles casos, e incluso de la inconveniencia de pretender hacerlo al precio de "traicionar" los propósitos de la norma. Asegurar la absoluta certeza del derecho implicaría hacer una composición de casos futuros bajo la ignorancia, y sólo podría hacerse a condición de "prejuzgar ciegamente"; de resolver por adelantado, pero también "a oscuras". Por tanto, es menester evitar la tentación de "exagerar" el carácter indeterminado de las normas jurídicas y recordar que el derecho tiene diversas técnicas para solucionar los problemas de indeterminación ${ }^{39}$.

Antes de las técnicas, el marco normativo sobre los menores girando en torno a la protección prioritaria de sus intereses constituye el horizonte de la certeza del derecho en relación a ellos. La certeza está "en los criterios y principios con que se forma toda la relación; en las leyes de la estructura y en las exigencias objetivas de la sociedad". La certeza no está tanto en la forma exterior de la ley, cuanto en la sustan-

36 Cfr. J. ELSTER, Juicios salomónicos. Las limitaciones de la racionalidad como principio de la decisión, trad. C. Gardini, Barcelona, 1995, pp. 116-118, 128-129.

37 Algo que ya había puesto de manifiesto Kelsen a propósito de la imposibilidad de responder de un modo racional al problema de la justicia, incluso cuando se limita a plantear los medios adecuados para lograr un fin, porque la relación entre medios y fin solo puede determinarse en base a la experiencia y solo cabe experimentar de un modo muy limitado en la vida social. $\mathrm{Cfr}$. $\mathrm{H}$. KELSEN, ¿Qué es justicia?, trad. A. Casamiglia, Barcelona, 1992, p. 44

38 En cuanto a su carácter controvertido, que cifra el Tribunal Supremo, en la ausencia de unanimidad social respecto a su contenido específico, de hecho el Tribunal no tiene dudas de cual es el interés de los menores en el asunto que decide, sino sobre cuál es el procedimiento más adecuado satisfacerlo. Cfr. J. J. INIESTA DELGADO, "La cláusula de salvaguarda del interés superior del menor en la resolución de conflictos: a propósito de la inscripción registral de los nacidos en el extranjero por maternidad subrogada", en J. A. GARCÍA AMADO (coord.), Razonar sobre derechos, Valencia, 2016, pp. 700-701.

39 H. L. A. HART, El concepto de Derecho, trad. G. R. Carrió, Buenos Aires, 1961, pp.160-163. 
cia interior de los principios de la ley". Es una "certeza sustancial", una "verdadera certeza" de la cual la certeza formal no es más que el "ropaje exterior" 40 .

La exigencia de atender al interés del menor, la consideración de ese interés como superior, prioritario o prevalente, como principio que da forma y contenido a las relaciones en que están implicados menores, es ya un elemento importante de certeza, seguridad y estabilidad en el tratamiento jurídico del menor. El nivel de certeza se incrementa cuando el principio adquiere consistencia en el contexto de los derechos del menor. Pero la certeza no es absoluta, ni es conveniente que así sea, para permitir su adaptación a las diversas circunstancias en que pueda proceder su aplicación. Que la norma que contiene el concepto referido sea general y abstracta, es decir que se aplique a todos los menores y en cualquier circunstancia, no significa que lo sea toda la experiencia jurídica, y mucho menos toda la práctica social. La incertidumbre de algunos conceptos jurídicos los hace permeables, flexibles, dúctiles, capaces de adaptarse a la compleja realidad social a la que el derecho se aplica. De ahí que no sea la incertidumbre de los conceptos el "enemigo natural del derecho", sino la arbitrariedad en su aplicación ${ }^{41}$.

El interés superior, en el contexto de los derechos del menor, cuenta con suficientes criterios que permiten determinarlo sin incurrir en arbitrariedad, aunque no exista unanimidad social sobre cual sea aquel interés en el caso concreto o cual sea el mejor medio de satisfacerlo. Su objetivo no es ampliar las facultades discrecionales sino limitarlas, aunque, tal vez podríamos convenir que, en la vida, los casos singulares y difíciles en que se ven involucrados menores, el derecho no puede ofrecernos más que la certeza como "promesa", y su triunfo no siempre está en lograrla sino en "aproximarse", siendo la "sola aproximación, en algunos casos, una conquista" 42.

En esta aproximación, la Convención Internacional de los Derechos del Niño, la Constitución española y la Ley Orgánica de Protección de la Infancia ya nos aportan algunos datos interpretativos objetivos, al menos intersubjetivos, sobre su significado a trasladar a los casos concretos. A resolver algunas dudas interpretativas contribuye el propio Comité de Derechos del Niño, en su Observación general n ${ }^{\circ}$. 14 (2013) sobre el derecho del niño a que su interés superior sea una consideración primordial (artículo 3, párrafo 1) ${ }^{43}$, según la cual el propósito general del interés superior del menor es promover un "verdadero cambio de actitud que favorezca el pleno respeto de los niños como titulares de derechos" 44 .

El interés superior del menor es el centro de todo el sistema de protección al menor, informador de toda decisión que les afecta, bien sea en sede familiar, legislativa,

40 G. CAPOGRASSI, “Introducción”, en F. LÓPEZ DE OÑATE, La certeza del Derecho, trad. S. Sentís Melendo y M. Ayerra Redin, Granada, 2007, p. XLI.

${ }^{41}$ F. LÓPEZ DE OÑATE, La certeza del Derecho, cit., p. 80.

42 E. J. COUTURE, "Prólogo a la edición en castellano", en F. LÓPEZ DE OÑATE, $L a$ certeza del Derecho, cit., p. XI.

43 Aprobada por el Comité en su $62^{\circ}$ periodo de sesiones (14 de enero a 1 de febrero de 2013). Puede consultarse en: http://www.unicef.cl/web/informes/derechos_nino/14.pdf

${ }_{44}$ Ibidem, Párr. 12, p. 5. 
administrativa o judicial, elemento de integración, en caso de laguna e interpretativo de toda situación en que esté involucrado. Para tan amplios propósitos adopta una triple dimensión: es un derecho sustantivo que implica que en cualquier asunto que estén afectados un niño en concreto, un grupo de niños o los niños en general, sus intereses se evalúen y sean tomados en cuenta. Un derecho de aplicación directa e inmediata que se traduce en obligaciones para los Estados. Es, en segundo lugar, un principio jurídico interpretativo fundamental en toda decisión que se refiera a menores. Y es, en tercer lugar, una norma de procedimiento que exigirá estimar en todo proceso y decisión que se vean afectados menores las posibles repercusiones sobre su persona. El interés superior del menor es un derecho que permite ejercer otros derechos, resolver conflictos entre derechos y ser sustento de ciertas exigencias procedimentales que se despliegan en un amplio catálogo de derechos específicos de protección a la infancia.

\subsection{Un derecho a proteger y promover derechos}

En primer lugar, el interés superior del menor es un derecho sustantivo, de aplicación directa e inmediata siempre que se tenga que adoptar cualquier decisión que afecte a un menor concreto o a la infancia en general. Como tal derecho genera una sólida obligación jurídica para los Estados y puede invocarse ante los tribunales ${ }^{45}$.

Como derecho tiene una sustantividad propia, es un derechos específico del menor, pero no es sustitutivo de otros derechos del menor sino complementario y, precisamente, dirigido a garantizarlos. Su objetivo no es otro que garantizar el disfrute pleno y efectivo de los derechos del menor y su desarrollo integral. Todos los derechos del menor, por tanto, forman parte de su interés superior. Alude a sus derechos presentes y futuros, a sus derechos y libertades civiles y a sus derechos económicos sociales y culturales; a su respeto, fomento, protección y preservación. La interdependencia de los distintos derechos es en los menores más evidente que en cualquier otro caso, por su especial vulnerabilidad y estar inmersos naturalmente en un proceso de desarrollo personal integral. En este sentido, necesidades, intereses y derechos aparecen íntimamente relacionados en la protección de los menores. Sus intereses son sus derechos, aquellos que le permiten satisfacer las necesidades materiales y afectivas precisas para su desarrollo integral, algunas a través de derechos y libertades civiles, otras de derechos económicos, sociales y culturales, entre los cuales, como bien señala el Comité de Derechos del Niño no hay una jerarquía; todos responden a su interés superior y ningún derecho puede verse perjudicado por una interpretación negativa ${ }^{46}$.

45 Así se pone de manifiesto en la Observación general no 14 en relación a la expresión "se atenderá" del artículo 3. 1 de la Convención Internacional de Derechos del niños, Ibidem, Párr. 6, p. 4.

46 Ibidem, Párr. 4, p. 3. Derechos del menor que comprenden, no sólo los que figuran expresamente en la Convención, sino todos los derechos reconocidos a todas las personas. De hecho al interpretar la referencia a las instituciones públicas y privadas de bienestar social a quien se dirige el artículo 3.2, la Observación general establece que deben entenderse todas las 
El interés del menor no se interpreta únicamente en el contexto de derechos de naturaleza protectora, habida cuenta de las limitaciones a que el menor se ve sometido por sus condiciones personales, alude también a derechos dirigidos a promover su autonomía y participación en los asuntos que le conciernen. En este sentido la Exposición de Motivos de la Ley Orgánica de Protección del Menor manifiesta con toda claridad que no existe un diferencia tajante entre las necesidades de protección del menor y las del desarrollo de su autonomía, siendo la mejor forma de garantizar social y jurídicamente la protección de la infancia promover su autonomía como sujetos ${ }^{47} \mathrm{y}$, por tanto, las limitaciones a sus derechos que pudieran derivarse del carácter evolutivo del menor, desde la perspectiva protectora, deberán interpretarse restrictivamente ${ }^{48}$.

Ningún derecho del menor, por lo tanto, puede verse perjudicado apelando a un interés superior que pueda ser una coartada para imposibilitar el ejercicio de sus derechos, ya que ha de entenderse siempre como un instrumento dirigido a potenciarlos. Y para potenciarlos, la perspectiva del menor, y no la del adulto a quien pueda corresponder interpretarlo, es la que ha de tomarse en consideración en la valoración de su interés; así lo pone de manifiesto la Observación general $n^{\circ} .14$ al señalar que "lo que a juicio de un adulto es el interés superior del niño no puede primar sobre la obligación de respetar los derechos del niño enunciados en la Convención" 49 .

El protagonismo del menor en la concreción de su interés no es sino consecuencia de una normativa que tiene como punto de partida y de llegada sus derechos, los derechos que le corresponden por ser persona y los derechos específicos como niño, que actúan complementariamente a los primeros para su salvaguardia y efectividad. Un derecho específico, como la consideración primordial del interés superior del menor, permite afianzar otros derechos de los menores como el derecho a ser informado y oído en todos los asuntos que le conciernen, el ejercicio directo de los derechos de la personalidad y aquellos que según sus condiciones de madurez pueda realizar por sí mismo, o el derecho de participar en todos los asuntos que le afecten.

\subsection{Un principio dirigido a resolver conflictos entre derechos, bienes e in- tereses}

El interés superior del menor es un derecho que protege a personas en una etapa de sus vidas especialmente vulnerable y que trata de compensar una desigualdad,

instituciones y decisiones que repercuten en los niños y la efectividad de sus derechos, no sólo las relacionadas con los derechos económicos, sociales y culturales sino también las que se ocupan de los derechos y libertades civiles. Y, en relación a los niños en situación de vulnerabilidad especial, señala que la protección ha de referirse al pleno disfrute de todos los derechos reconocidos en la Convención y en otras normas de derechos humanos relacionadas con sus situaciones específicas (Ibidem, Párr. 75, p. 17).

47 A propósito de la relación entre la naturaleza de distintos derechos del menor, cfr. J. EEKELAAR, "Importance of thinking that Children have Rights", en Ph. ALSTON, S. PARKER y J. SEYMOUR (eds.), Children Rights and the Law, Oxford, 1991, pp. 231-232.

48 Una afirmación que se reitera en los artículos 2.1 y $2.3 \mathrm{f}$ ).

49 http://www.unicef.cl/web/informes/derechos_nino/14.pdf, Párr. 4, p. 3. 
con respecto a otros sujetos que ya han superado aquella etapa y la vulnerabilidad a ella asociada. El objetivo de compensar la desigualdad comprende lógicamente que se haga a través de una medida de ventaja, en términos de prioridad o preferencia, en la valoración de los intereses menor. De ahí que en la Convención Internacional sobre derechos del niños, el interés del menor es "superior" y su valoración una "consideración primordial".

Desde este perspectiva, el calificativo de superior, o la consideración primordial de los intereses del menor, tienen un carácter relacional que adquiere todo su potencial cuando opera en conflicto con otros intereses, bienes o derechos. El interés del menor es superior e insistir en las dudas interpretativas sobre si todos los intereses del menor son superiores, o que pueda resultar una consideración más entre otras, puede conducir a una banalización de un derecho específico del menor dirigido precisamente a la protección y promoción de sus derechos y que no trata solo de evitar que se le causen perjuicios, sino que las circunstancias que le rodean le sean especialmente favorables para su desarrollo personal ${ }^{50}$.

En consonancia con esta visión, la Observación general $n^{\circ}$. 14 interpreta que la expresión "consideración primordial" significa que el interés superior del niño no puede estar al mismo nivel que las demás consideraciones, no es una de tantas, sino que ha de tener una máxima prioridad ${ }^{51}$; y el artículo 2.1 de la Ley Orgánica de Protección del Menor, señala que primará el interés superior de los menores "sobre cualquier otro interés legítimo con que pudiera concurrir". Por tanto, los eventuales problemas de certeza en los casos en que concurran diversos intereses del menor, o el interés del menor con un tercero, no deben versar sobre la prioridad, la superioridad o la preferencia del interés del menor-sobre lo que no cabe dudar-, sino sobre el carácter automático o no de aquella prioridad, del sacrificio de otros intereses y sobre cuales sean los criterios de ponderación cuando tal situación se produzca, en caso de que las decisiones ante el conflicto no sean automáticas.

\subsubsection{El interés superior del menor árbitro en los conflictos entre distintos derechos del menor}

El interés del menor es un término genérico y abstracto que engloba diversos bienes, derechos, necesidades e intereses de los menores y también el punto de referencia para valorar aquel o aquellos que deban prevalecer, en caso de que sean varios los que concurran, y no puedan ser satisfechos al tiempo.

El conflicto de derechos aparece intrínsecamente ligado al problema de los límites a su ejercicio. En el caso del menor estos límites se vinculan a aquellas circunstancias personales que justifican su protección especial, siendo la primera de ellas las deficiencias de conocimiento y voluntad, que determinan la falta de madurez para tomar decisiones racionales y asumir las consecuencias de aquellas decisiones. Sobre

50 Cfr. J. I. GRANDE ARANDA, "El principio del interés superior del niño”, en I. LÁZARO GONZÁLEZ (coord.), Los menores en el Derecho español, Madrid, 2002, p. 97.

${ }_{51}$ http://www.unicef.cl/web/informes/derechos_nino/14.pdf, Párr. 39, p. 11. 
esta base se plantean las restricciones o limitaciones de los derechos de libertad del menor, aquellos vinculados a su autonomía, incluyendo la participación en la propia determinación de cuál sea su interés superior en un caso concreto.

Mill ya entendió la situación de los menores como una excepción a la idea de que toda persona es el mejor juez de sus propios intereses. En la misma línea MacCormick pone de manifiesto que los niños no son siempre quienes mejor pueden valorar lo que es bueno para ellos, tanto que no es infrecuente que perciban como contrarios a sus intereses los derechos más importantes para su bienestar a largo plazo ${ }^{52}$. Freeman, acertadamente, señala que tomarse en serio los derechos del niño significa reconocer su capacidad para tomar decisiones, pero también ser conscientes de los peligros que encierra una libertad total ${ }^{53}$.

Tomando en serio los derechos del menor, y el interés superior que se dirige a satisfacerlos, las limitaciones al ejercicio de sus libertades han de estar condicionadas siempre por derechos del menor que se consideren prioritarios en el caso concreto que se pretenda aquella limitación, siendo necesario tener en cuenta las condiciones de madurez específicas del menor que, en última instancia, son las que justifican la intervención de terceros en sus decisiones. La solución, por tanto, apelando al interés superior del menor en un conflicto entre sus derechos de autonomía y otros derechos no puede ser automática pues depende, de un lado, de la variable madurez del menor según la etapa de desarrollo en que se encuentre y de sus características personales, $\mathrm{y}$, de otro lado, de cuales sean los derechos que se vean afectados por sus propias decisiones y que pueden comprometer sus intereses en mayor o menor medida.

Pese a estas variables que impiden que se pueda dar una única interpretación al interés superior del menor para resolver los conflictos entre los derechos de libertad del menor y otros derechos, el concepto y su contexto nos aporta algunas certezas. En primer lugar, como ya se ha señalado las limitaciones a los derechos del menor han de ser interpretadas restrictivamente, con el objetivo de potenciarlos en el futuro, en caso de que no proceda su ejercicio en el presente. En segundo lugar, la autonomía del menor ha de promoverse y, por tanto, la voluntad del menor ha de ser uno de los criterio a tener en cuenta en los conflictos entre su libertad y otros derechos, siendo su peso en la valoración tanto mayor cuanto mayor sea la madurez del menor ${ }^{54}$.

El fomento de su autonomía, y la toma en consideración de su voluntad, en cualquier situación que afecte al menor y requiera valorar sus distintos intereses, es reforzada por distintos derechos reconocidos al menor, tanto en la Convención

52 Cfr. N. MacCORMICK, "Los derechos de los niños: una prueba de fuego para las teorías del derecho", cit., p. 137.

${ }_{53}$ Cfr. M. D. A. FREEMAN, "Talking children's rights more seriously”, en Ph. ALSTON, S. PARKER y J. SEYMOUR (eds.), Children Rights and the Law, cit., pp. 65-66.

54 La Exposición de Motivos de la Ley Orgánica de Protección del Menor señala que la mejor forma de garantizar social y jurídicamente la protección de la infancia es promover la autonomía del menor. El interés del menor debe valorarse desde el punto de vista subjetivo, teniendo en cuenta los deseos y opiniones del sujeto afectado, cfr. M. J. SANTOS MORÓN, "Menores y derechos de la personalidad. La autonomía del menor", Anuario de la Facultad de Derecho Universidad Autónoma de Madrid, nº 15, 2011, p. 80. 
Internacional de los Derechos del Niño como en nuestra legislación sobre protección del menor. Así, la Convención en su artículo 12 establece que los Estados parte "garantizarán al niño que esté en condiciones de formarse un juicio propio el derecho a expresar su opinión libremente" en todo los asuntos que le afecten, teniéndose "debidamente en cuenta sus opiniones", en función de la edad y madurez, a cuyo fin se le dará "la oportunidad de ser escuchado", "ya sea directamente o por medio de un representante o de un órgano adecuado". Ahondando en la necesidad de que el niño pueda expresarse, sea escuchado y tenido en cuenta, la Observación general $n^{\circ} .14$ señala que se ha de proporcionar a los niños información adecuada, crear las condiciones necesarias para que puedan expresar su punto de vista y que a sus opiniones se les de la importancia debida en todos aquellos asuntos que les conciernen ${ }^{55}$. Por su parte, el artículo 9 de la Ley Orgánica de Protección del Menor, recoge el derecho del menor a ser oído y escuchado, "teniéndose debidamente en cuenta sus opiniones, en función de su edad y madurez". Un derecho que podrá ejercitar por sí mismo cuando la madurez sea "suficiente" - a partir de 12 años o cuando así se valore por personas especializadas-, a no ser que no sea posible o que "no convenga al interés del menor" puesto de manifiesto a través de una resolución motivada.

A la luz de estos derechos reconocidos, dirigidos a fomentar la autonomía del menor, y que constituyen criterios a valorar para determinar en el caso concreto su superior interés, el menor no tiene garantizado que su decisión prevalezca, pero sí que sea tenida en cuenta en el proceso de resolución del conflicto sobre sus derechos. El suyo no será el único criterio, quizás no el decisivo, pero es una certeza su participación en el proceso de determinación de su interés, a través de sus derechos a ser informado, a expresarse, a ser escuchado y a que sus opiniones sean valoradas y tenidas en cuenta.

La autonomía del menor se promueve, pero no se garantiza en todos sus extremos, porque la protección del menor va dirigida a preservar todos sus derechos, a fin de que pueda desarrollarse plenamente como adulto. Los derechos a preservar que permitan tal desarrollo, y que se vean comprometidos en el caso concreto, serán el segundo criterio a valorar específicamente para determinar el superior interés del menor en estos conflictos entre derechos. Así pues, la referencia a los derechos del menor no tendrá que ser sólo en presente, sino contar con una previsión de futuro, del tal manera que podría considerarse irracional, por contrario a la protección de los intereses del menor, amparar aquellas decisiones del menor que pudieran perjudicarlo de forma irreversible para el futuro ${ }^{56}$.

La Sentencia del Tribunal Constitucional 154/2002, de 18 de julio refleja los dos principales criterios a valorar para determinar el interés superior del menor, en su función de árbitro, en caso de conflicto entre diversos derechos del menor. En este supuesto, un menor de 13 años, y antes sus padres, se opusieron, por motivos religiosos, a que se le hiciera una transfusión de sangre autorizada por el juez al con-

55 http://www.unicef.cl/web/informes/derechos_nino/14.pdf, Párr. 15 g), p. 6.

56 Cfr. T. PICONTÓ NOVALES, En las fronteras del Derecho. Estudio de casos y reflexiones generales, Madrid, 2000, p. 32. 
siderarla necesaria para mantener con vida al menor. El Tribunal reconoce la plena titularidad del menor de los derechos a la libertad religiosa y a la integridad física, si bien también considera que su ejercicio ha de modularse en función de su madurez, de los derechos afectados por su decisión y la intensidad del perjuicio que le pudiera causar $^{57}$. En cuanto a la madurez del menor, el Tribunal Constitucional considera que, aunque sus convicciones religiosas eran claras y su decisión debía tenerse en cuenta, no había datos suficientes que permitieran concluir con certeza que el menor tuviera la madurez de juicio necesaria para asumir una decisión vital. En cuanto al derecho afectado por la decisión del menor, siendo este la vida y conduciendo su decisión de forma definitiva e irremediable a la muerte, entendió que procede limitar sus derechos a la libertad religiosa e integridad física en aras a la protección de su propia vida, como única forma de hacer posible el futuro ejercicio de todos los demás derechos ${ }^{58}$.

La consideración del presente y del futuro del menor en la determinación de su interés superior, permitirá también delimitar el contenido de algunos de sus derechos en relación a la vida familiar. La familia se ha revelado como el ámbito más apropiado y más beneficioso para el desarrollo del menor, el marco vital propicio en el que adquirir y desarrollar las capacidades y potencialidades, tanto materiales, como afectivas, habilidades psíquicas, personales y sociales necesarias para una futura vida independiente, autónoma, libre y responsable. En consecuencia, la normativa relativa a los menores ha recogido profusamente el derecho de niños y niñas a ser criados y educados en un medio familiar. Además, dentro de las distintas opciones de vida familiar que pueden plantearse, se considera que la familia biológica es, en primera instancia y preferentemente, la más beneficiosa para el desarrollo de los niños y niñas. De tal manera que, prioritariamente, serán los padres biológicos a quienes corresponda el cuidado, protección y satisfacción de derechos de hijos e hijas. Abundando en esta idea, el derecho a ser criado y educado por su familia se concreta en una serie de derechos para el menor: derecho a no ser separado de su padres biológicos; a la investigación de la paternidad; en caso de separación de sus padres, derecho a tener contacto ellos y a retornar, si es posible, a su familia biológica; y a que la primera intervención de los poderes públicos en la protección del menor lo sea en un nivel de cooperación con la familia, dirigida a procurarla los bienes y recursos precisos para que pueda desarrollarse en su seno la vida del menor ${ }^{59}$.

57 FJ 9 STC 154/2002; ver también FJ 5 STC 141/2000.

58 FJ 10, STC 154/2002, de 18 de julio.

59 La Convención Internacional de Derechos del Niño, reconoce en su artículo 7 el derecho del niño a conocer a sus padres y a ser cuidado por ellos; el artículo 8 el derecho a preservar su identidad; el artículo 9 el derecho del niño a no ser separado de sus padres y, en caso de estarlo, a mantener relaciones personales y contacto directo con ambos padres de modo regular. En esta línea de protección del menor, la Ley Orgánica de Protección del Menor, partiendo de que es interés del menor que su "vida y desarrollo tenga lugar en un entorno familiar adecuado y libre de violencia" se propone priorizar su permanencia en la familia de origen y preservar el mantenimiento de sus relaciones familiares, siempre que sea posible y positivo para el menor. Cuando sea necesario acordar una medida de protección, opta en primer término por el acogimiento familiar frente al residencial; y cuando el menor hubiera sido separado de su núcleo familiar, se hacer preciso valorar 
Ahora bien, lógicamente, el interés superior del menor es satisfecho, a través de sus derechos a la vida familiar, cuando su familia en concreto resulta ser el cauce adecuado para el desarrollo de sus necesidades, derechos e intereses, no cuando sea un obstáculo a los mismos ${ }^{60}$. En tales circunstancias el menor se encuentra en una situación especialmente vulnerable de la que él mismo no puede protegerse, requiriendo entonces la protección de los poderes públicos, mediante la intervención en su vida familiar y, en su caso, la limitación de algunos de sus derechos para hacer prevalecer y preservar otros.

Pero tal intervención, limitativa de algunos de los derechos del menor, justificados en su propio interés, está sometida a ciertas garantías y certezas derivadas de otros derechos y también en su interés. En primer lugar, y ya mencionado, se ha de procurar la mínima intervención posible en la vida familiar del menor, priorizando las medidas de apoyo a la familia para que, en la medida de lo posible, el menor pueda permanecer en ella. Otras medidas de intervención han de ser proporcionales al grado de desprotección del menor, siendo la separación de su ámbito familiar un remedio siempre excepcional y subsidiario. Cuando tal situación excepcional se produzca se han de adoptar medidas que permitan el retorno a la familia, teniendo en cuenta que la familia siempre es el mejor medio para el adecuado desarrollo del menor, por lo tanto se debe optar por las soluciones familiares antes que por las residenciales ${ }^{61}$.

\subsubsection{El interés superior del menor frente a intereses de terceros}

Cuando el interés superior del menor se enfrente a un conflicto entre sus propios derechos será preciso determinar cuál resulta prevalente o prioritario y proceder a sa-

las posibilidades y la conveniencia de su retorno, "teniendo en cuenta la evolución de la familia desde que se adoptó la medida protectora y primando siempre el interés y las necesidades del menor sobre las de la familia" (art. 2. 2 c.). Asimismo se prevé que intervención sobre el entorno ha de ser gradual en función de la situación de riesgo en que se encuentre el menor, limitándose, si es posible, a intentar eliminar dentro de la propia familia los factores de riesgo (art. 17) y sólo en situaciones graves de desamparo se debe proceder a separar al menor de su familia (art. 18).

${ }^{60}$ Cfr. E. ROCA, Familia y cambio social (De la "casa" a la persona), cit., p. 223. En consonancia, con las funciones propias de la familia y, en particular, de los padres en relación a sus hijos, la Convención Internacional sobre los Derechos del Niño, establece en su artículo 5 el respeto por las responsabilidades, derechos y deberes de los padres o los miembros de la familia ampliada, siempre que se ejerzan de forma apropiada y en consonancia con los derechos del menor; y el artículo 18 señala que la preocupación fundamental de los padres, a quienes incumbe la responsabilidad primordial de la crianza y desarrollo del niño, será su interés superior. De aquí que en el reconocimiento de los derechos del menor en el ámbito familiar se contemple la posibilidad de limitarlos, cuando mantenerlos resulte contrario al interés superior del niño.

${ }_{61}$ Cfr. J. M DE TORRES PEREA, Interés del menor y derecho de familia. Una perspectiva multidisciplinar, Madrid, 2009, p. 57. Así resulta avalado por el Tribunal Europeo de Derechos Humanos, que afirma que la protección de la vida familiar por el artículo 8 del Convenio Europeo de Derechos Humanos, exige que el alejamiento del menor de su contexto familiar sea una medida extrema, a la cual sólo se debe recurrir como ultima ratio, justificada en su protección frente a un peligro inmediato. Caso Paradiso y Campanelli contra Italia, Sentencia de 27 de enero de 2015. http://hudoc.echr.coe.int/eng\#\{ "itemid":["001-170359". 
crificar o limitar otro, pero en cualquier caso, siempre triunfa un derecho del menor, el que mejor represente su interés superior. Pero estos no serán los únicos conflictos a los que se verá expuesto el menor en sus relaciones sociales. La variedad y complejidad de las diferentes relaciones en que los menores puedan estar inmersos abocará en la confluencia, junto a sus intereses, de otros intereses de diversa índole: intereses de otras personas, particularmente sus padres u otros miembros de su familia y de su entorno, los intereses de los niños en general u otros intereses, que pueden llegar a ser catalogados como de orden público.

Stuart Mill ya se planteó esta problemática, referida al conflicto entre los intereses de los hijos y de los padres, a propósito de la prohibición de la disolución matrimonial justificada en la prioridad de los intereses de los hijos; manifestando su desacuerdo ante una limitación semejante a la libertad de los adultos, "como si el interés de los niños lo fuera todo y el de las personas adultas nada" ${ }^{2}$. Elster advierte que la superioridad del interés del menor sobre los intereses de los adultos, puede conllevar decisiones injustas, en tanto desconocedoras de los derechos e intereses de los padres ${ }^{63}$. Llama también la atención sobre lo que él considera el "efecto perverso" de un principio que puede "atentar contra sí mismo", cuando al promover los intereses de un niño concreto obre contra los intereses de los niños en general ${ }^{64}$.

Pues bien, ante tales conflictos ya se ha puesto de manifiesto que una primera certeza es que el interés del menor no está en el mismo plano que otros intereses, es superior y debe considerarse preferentemente frente a ellos. Los diversos derechos, e intereses en conflicto, no están en el mismo nivel de jerarquía valorativa y no lo están por la misma razón que justifica la existencia de derechos específicos para los menores. Los menores parten de una situación de desigualdad, en relación a los adultos, y el interés del menor, como otros derechos específicos, tratan de compensar aquella desigualdad, de fortalecer su posición jurídica desde una posición de debilidad de partida ${ }^{65}$. Ahora bien, que sean prioritarios o preferentes no significa que sean exclusivos o excluyentes, así pues las dudas no se van a plantear en el nivel de la prioridad, pero si en el del carácter automático de la preferencia y en el de la valoración de los distintos intereses que puedan concurrir junto a los del menor.

${ }^{62}$ Cfr. J. S. MILL, Sobre la libertad, cit., p. 192.

${ }_{63}$ Cfr. J. ELSTER, Juicios salomónicos, cit., p.115.

${ }^{64}$ Ibidem, p. 123. Señala como ejemplo de estos supuestos cuando el interés del menor puede generar incentivos o expectativas parentales por incumplimiento de leyes en que se ha valorado el interés de todos los niños. Una situación que podría ejemplificar el supuesto de Elster es el tratado por la Sentencia del Tribunal Supremo 835/2013, de 6 de febrero de 2014, sobre la inscripción de la filiación de dos niños nacidos por contrato de gestación subrogada en favor de los padres de deseo. En su Fundamento Jurídico Quinto. 7. señala el Tribunal que han de ser tomados en cuenta otros bienes jurídicos como impedir la mercantilización de la filiación, y en el apartado 8 , añade que siendo cierto que no reconocer la filiación establecida en California puede suponer un perjuicio para la posición jurídica de los menores cuya reconocimiento se pretende, también lo sería determinar aquella filiación en favor de quien realiza el encargo, pues atenta contra la dignidad del menor al convertirlo en objeto de tráfico mercantil.

65 Cfr. F. RIVERO HERNÁNDEZ, El interés del menor, cit., pp. 74-75. 
La Observación general $\mathrm{n}^{\mathrm{o}}$. 14 aclara el valor de la superioridad del interés del menor ante otros intereses, afirmando que los posibles conflictos tendrán que resolverse caso por caso "sopesando cuidadosamente" los intereses de todas las partes y encontrando un "compromiso adecuado". También dejará claro que, si no es posible armonizarlos, "el derecho del niño a que su interés superior sea una consideración primordial significa que los intereses del niño tienen la máxima prioridad y no son una de tantas consideraciones. Por tanto, se debe conceder más importancia a lo que sea mejor para el niño" "66. Por su parte, la Ley Orgánica de Protección del Menor, después de establecer, en el apartado 1 del artículo 2, que el interés superior de los menores debe primar sobre cualquier otro interés legítimo con que pudiera concurrir, entiende que la prioridad no es absoluta; que el interés del menor puede quedar delimitado o moderado por otros derechos, bienes o intereses jurídicamente reconocidos. En consecuencia dispone, en el apartado 4 del mismo artículo, que en caso de concurrir "cualquier otro interés legítimo junto al interés superior del menor deberán priorizarse las medidas que, respondiendo a este interés, respeten también los otros intereses legítimos presentes", debiéndose "valorar en todo caso los derechos fundamentales de otras personas que pudieran verse afectados".

La prioridad no significa, por tanto, automaticidad en la aplicación del interés del menor y descarte de otros intereses. Será necesario valorar la importancia en el caso concreto de otros intereses que concurran con los del menor y decidir cual prevalecerá en tal caso. Pero aunque no hay certeza de la prevalencia absoluta del interés del menor en todos los casos, su carácter prioritario y preferente permitiría admitir como certeza que el desplazamiento del interés superior del menor por otros intereses ha de ser excepcional ${ }^{67}$. Así lo han entendido tanto el Tribunal Constitucional como el Tribunal Europeo de Derechos Humanos, para quienes el criterio que ha de presidir las decisiones en que intervengan menores debe ser "necesariamente" el del interés prevalente del menor. Aclarará el Tribunal Constitucional que, cuando el ejercicio de alguno de los derechos de los progenitores pueda repercutir de un modo negativo en el desarrollo de la personalidad del hijo menor, el interés de los progenitores debe ceder frente al del menor, sean cuales sean los motivos de la repercusión negativa para el menor e, incluso, aunque no llegue a producirse el perjuicio, bastando con que exista un riesgo relevante de que pueda llegar a producirse ${ }^{68}$. Ahora bien, tal interés ha de ser ponderado con otros intereses, bienes y derechos que, aunque no tengan el mismo rango, no resultan desdeñables ${ }^{69}$.

${ }^{66}$ http://www.unicef.cl/web/informes/derechos_nino/14.pdf, Párr. 39, p. 11.

${ }_{67}$ Ibidem, Párr. 97, p. 20.

68 STC 176/2008, de 22 de diciembre, FJ 6.

69 Sentencias del Tribunal Constitucional: 141/2000, de 29 de mayo, FJ 5; 124/2002, de 20 de mayo, FJ 4; 144/2003, de 14 de julio, FJ 2; 71/2004, de 19 de abril, FJ8; 11/2008, de 21 de enero, FJ 7; 176/2008, de 22 de diciembre, FJ 6. Sentencias del Tribunal Europeo de Derecho Humanos: caso Olsson, de 24 de marzo de 1988; caso Nielsen, de 28 de noviembre de 1988; caso Andersson, de 25 de febrero de 1992; caso Hoffmann, de 23 de junio de 1993; caso EP. contra Italia, de 16 de noviembre de 1999; caso Salgueiro Da Silva Mouta contra Portugal de 21 de diciembre de 1999. 
El interés superior del menor es operativo frente a cualquier tipo de decisión en que se vean afectados menores, ya sea un menor en particular o los niños en general, lo cual hace posible que el interés de un niño en concreto pueda resultar contrario a los intereses generales de la infancia. La Observación general $\mathrm{n}^{\circ} .14$ trata de este eventual conflicto de intereses y tras señalar que el interés superior del menor se concibe como un derecho colectivo y como un derecho individual, constata que el interés de un niño en particular puede resultar distinto a los intereses relativos a los niños en general, en cuyo caso será preciso que el interés superior del niño sea evaluado individualmente ${ }^{70}$. Por su parte, la Ley Orgánica de Protección del Menor, en sus artículos 2. 2 y 2.3, recoge distintos criterios a tener en cuenta en la interpretación y aplicación "en cada caso" del interés superior del menor. Así viene siendo tratado también este conflicto de intereses por la jurisprudencia del Tribunal Constitucional ${ }^{71}$. En estos supuestos, por lo tanto, la prioridad del interés superior del menor se corresponde con el de un niño o niña en circunstancias concretas, el de un niño particular frente a los niños en general. Al respecto, se ha llamado la atención críticamente sobre el excesivo peso en el ámbito jurídico que, en relación al interés del menor, están teniendo los discursos científicos sobre el bienestar de los niños en general, sin tomar en consideración que tales estudios responden a situaciones complejas, que a veces tienen resultados ambiguos y que, lógicamente, no pueden recoger todas las diferencias y divergencias que se producen en cada menor en particular ${ }^{72}$.

La superioridad del interés del menor tendrá eficacia en la confrontación con otros intereses que pueden ser configurados como de orden público. Sobre este preciso conflicto de intereses, se han de tener en cuenta también algunas certezas. Por un lado, que el Tribunal Constitucional, en su Sentencia 141/2000, de 29 de mayo, ha calificado a la normativa referida a menores como "estatuto jurídico indisponible de los menores de edad", con características de orden público. Por otro lado, el Tribunal Europeo de Derechos Humanos ha señalado que cuando se trata de establecer un equilibrio entre los intereses del Estado y de los individuos, cuando están implicados menores, su interés superior debe prevalecer, incluso frente a normas de orden público $^{73}$. A mayor abundamiento, el orden público no puede ser una carta blanca que justifique cualquier medida sin tomar en consideración el interés superior del menor; es más el interés superior del menor ha de valorarse con independencia de

70 http://www.unicef.cl/web/informes/derechos_nino/14.pdf, Párrs. 23 y 24, p. 8.

71 La necesidad de individualizar los intereses del menor con referencia expresa a la situación del caso concreto ha sido puesta de manifiesto, entre otras, por la STC 124/2002, de 20 de mayo, FJ 6 y la STC 138/2014, de 8 de septiembre, FJ 5.

72 Cfr. T. PICONTÓ NOVALES, "Ruptura familiar y coparentalidad: Un análisis comparado", en ID. (ed.), La custodia compartida a debate, Madrid, 2012, pp. 69-70. Ver también, J. ELSTER, Juicios salomónicos, cit., p. 115.

73 Sentencias de 26 de junio de 2014, casos Menensson y Labassee contra Francia http://hudoc. echr.coe.int/eng? $i=001-145179 * \#\{$ “itemid":["001-145179*”]\}; http://hudoc.echr.coe.int/eng?i=001145180*\#;"itemid":["001-145180*”]\}; Foulon et Bouvet contra Francia, 21 de julio de 2016 http://hudoc.echr.coe.int/eng\#;“itemid”:[“001-164968”]\}; Laborie contra Francia, 19 de enero de 2017 http://hudoc.echr.coe.int/eng\#;“itemid”:[“001-170369”]\} 
la calificación jurídica - de ilegalidad- de los hechos en el país donde se pretenda el reconocimiento de los derechos del menor amparados por el Convenio ${ }^{74}$.

\subsection{Una norma de procedimiento: motivación, flexibilidad, estabilidad y celeridad}

El interés superior del menor es una norma de procedimiento y sobre tal carácter se construyen algunas certezas destinadas a limitar la discrecionalidad, y desterrar la arbitrariedad, para su determinación en el caso concreto. El Comité de Derechos del Niño, en su Observación general $n^{\circ}$. 14 interpreta que, como norma de procedimiento, el interés superior del menor obliga a los Estados a establecer procesos transparentes y objetivos, con estrictas garantías destinadas a evaluar y determinar en qué se concreta en cada caso el interés del niño o niña. Para dar efectividad a aquellas garantías el Comité invita a que se preste especial atención, en todo proceso en que sea preciso evaluar el interés superior, al derecho del niño a expresar su opinión; a la intervención de profesionales cualificados y especializados; a la evaluación de las previsibles consecuencias de cada posible solución para el niño, dadas sus características individuales y las experiencias anteriores; a la representación letrada; a la motivación, justificación y explicación de las decisiones; a los mecanismos para recurrir y revisar las decisiones; y al seguimiento y evolución del impacto de las decisiones ${ }^{75}$. La Ley Orgánica de Protección del Menor en su artículo 2.5 -modificado por la Ley Orgánica de 29 de julio de 2015- recoge las garantías procesales debidas en interés superior del menor, en concreto: el derecho del menor a ser informado, oído y escuchado, y a participar en el proceso; la intervención en el proceso de profesionales cualificados o expertos; la participación de progenitores, tutores, representantes legales del menor o un defensor judicial y del Ministerio Fiscal; el derecho a la asistencia jurídica gratuita; la adopción de una decisión que incluya en su motivación los criterios utilizados, los elementos aplicados al ponderar los criterios entre sí y otros intereses presentes y futuros, y las garantías procesales respetadas; la existencia de recursos que permitan revisar la decisión adoptada, bien porque no haya considerado el interés superior del menor como primordial, o porque el desarrollo del menor, o cambios significativos en las circunstancias que motivaron dicha decisión, hagan necesaria su revisión.

Son garantías procesales que se erigen en derechos del propio menor, debiendo quedar patente su respeto en la motivación de la decisión. El Tribunal Constitucional deja constancia de la trascendencia de la motivación como garantía de satisfacción del interés superior del menor. A pesar de advertir que la determinación del interés del menor en un caso concreto es una cuestión de jurisdicción ordinaria y no le corresponde a él una

74 Caso Paradiso y Campanelli contra Italia, 27 de enero de 2015 (http://hudoc.echr.coe. int/eng\#\{"itemid":["001-170359”]\}). No obstante, pese a la vulneración apreciada del derecho a la vida familiar, no consideró el Tribunal que el niño debía reiniciar relaciones familiares con los demandantes puesto que el niño ya estaba integrado en una nueva familia. Cfr. J. MONTERONI, "Paradiso, Campanelli y un contrato internacional de maternidad subrogada ante el Tribunal Europeo de Derechos Humanos", Prudentia Iuris, n. 8, 2015, pp. 273-279.

75 http://www.unicef.cl/web/informes/derechos_nino/14.pdf, Párrs. 85 a 99, pp. 19-21. 
potestad revisora, lo que si le compete es comprobar que el interés superior del menor ha sido tenido en cuenta fundadamente en la motivación de la resolución y no se ha vulnerado ningún derecho del menor ${ }^{76}$. Es más, hará que sobre la evaluación del interés superior del menor gire la adecuación constitucional de la motivación de cualquier resolución en que esté involucrado un menor; y considera lesiva al interés superior, legal y constitucionalmente inviable, una motivación y fundamentación en derecho ajena a aquel criterio ${ }^{77}$. Entiende que, para que la motivación esté suficientemente fundada en el interés superior, no basta con afirmaciones que pretendan hacer una justificación en términos generales, sino que es preciso una valoración que haga constar expresamente en la resolución la identificación, en el caso concreto, de los bienes y derechos en juego, a fin de poder calibrar la necesidad y proporcionalidad de la medida. Puede concluirse que las exigencias de la motivación no garantizan el acierto, pero al menos si permiten la razonabilidad y la ausencia de arbitrariedad en las decisiones ${ }^{78}$.

Junto a aquellas exigencias en la motivación, las características propias de los menores hacen preciso valorar específicamente el impacto del factor tiempo en sus vidas, como uno de los elementos que van a ser determinantes en su interés ${ }^{79}$. El niño y la niña son sujetos en proceso de crecimiento y maduración, a lo largo del cual varían sus necesidades, sus intereses, sus posibilidades y su capacidad para afrontarlos. Como consecuencia del especial efecto del tiempo en los menores, las decisiones que a ellos se refieran han de ser flexibles, adaptables a su propia evolución, es decir, no definitivas, ni irreversibles ${ }^{80}$.

Pero además la infancia es un periodo de la vida crucial en el desarrollo de la personalidad y determinante en cómo será el sujeto en el futuro como adulto. Por estos motivos, el interés superior del menor ha de valorarse, tanto en clave de presente -interés actual- como de futuro - predecibilidad- ${ }^{81}$, representando, junto a la flexibilidad, la estabilidad en las medidas que se adopten con respecto a ellos dos referencias ineludibles en la determinación de sus intereses. La Observación general no ${ }^{\circ} 14$ consciente de la importancia de estas características propias del menor señala que en su interés se ha de prestar especial atención a las posibles hipótesis de desarrollo del niño, evaluando la continuidad y la estabilidad de su situación presente y futura ${ }^{82}$.

$\begin{array}{ll}76 & \text { ATC 28/2001, de } 1 \text { de febrero de } 2001 . \\ 77 & \text { Cfr. FJ } 6 \text { STC 16/2016, de } 1 \text { de febrero de } 2016 . \\ 78 & \text { Ibidem, FJ 7. } \\ 79 & \text { Cfr. STC 124/2002, de } 20 \text { de mayo, en su FJ } 6 \text { señala que desde el prevalente interés su- }\end{array}$ perior del menor (en este caso si procede o no el retorno de los menores con su madre biológica) es relevante el tiempo transcurrido desde la decisión precedente (desde que fueron separados de ella) y conocer el estado actual de los menores en la familia acogedora, en lo que tiene mucho que ver el tiempo que han pasado con ella.

80 http://www.unicef.cl/web/informes/derechos_nino/14.pdf, Párr. 93, p. 20.

${ }^{81}$ Cfr. N. CAMPS MIRABET, "El principio del interés superior del menor: marco normativo internacional y aplicación en el Derecho”, en A. M. PADIAL ALBÁS y M. D. TOLDRÀ ROCA (coords.), Estudios jurídicos sobre la protección de la infancia y la adolescencia, Valencia, 2007, p. 27. Ver también M. LIEBEL, "Sobre el interés de los niños y la evolución de sus facultades", Anales de la Cátedra Francisco Suárez, n 49, 2015, pp. 45-46.

82 http://www.unicef.cl/web/informes/derechos_nino/14.pdf, Párr. 84. p. 18. 
Junto a la flexibilidad y estabilidad, la celeridad vendría a completar las garantías procesales que, en función del factor tiempo, permiten realizar una valoración del interés superior del menor ${ }^{83}$. Y tratándose de aspecto procesales, no puede dejarse a un lado el coste que para el menor tiene el procedimiento ${ }^{84}$. La dilación, que en los procesos en general constituye una de las causa de incertidumbre jurídica, de desconfianza en el derecho y de percepción de injusticia ${ }^{85}$, en el caso de los menores puede ser causante de perjuicios irreparables en asuntos de gran trascendencia para su equilibrio personal y familiar, tanto presente como futuro. Es, en este sentido, de interés del menor la celeridad en los procedimientos en que estén inmersos.

El Tribunal Europeo de Derechos Humanos ha tenido ocasión de pronunciarse en diferentes ocasiones sobre la violación del artículo 8 del Convenio, protección de la vida privada y familiar, en relación al alargamiento de los procedimientos y el interés superior del menor, en concreto al tratar cuestiones atinentes a las relaciones de los menores con los padres o las madres que no conviven con ellos. El Tribunal deja constancia de que el mero transcurso del tiempo, sin tomar decisiones sobre las relaciones de los padres con sus hijos, puede tener consecuencias irremediables para el menor y, por ello, las autoridades no puede dejar consolidar una situación de hecho simplemente dejando pasar el tiempo. Concluye que, siendo el tiempo en los procesos sobre menores potencialmente determinante, la celeridad es fundamental para garantizar sus derechos. En este sentido, corresponde a los poderes públicos, no solo abstenerse de injerencias en la vida privada, sino afrontar sus obligaciones positivas en aras a garantizar el respeto del derecho del menor a que las relaciones con sus padres sean reguladas sobre la base de elementos pertinentes y no por el mero paso del tiempo. De la necesidad de asegurar los procedimiento en tiempo razonable, como asunto de interés superior del menor, deriva que la adecuación de las medidas

83 La Sentencia del Tribunal Constitucional 16/2016, de 1 de febrero, da buena cuenta de la importancia del transcurso del tiempo en la evaluación del interés del menor en un procedimiento de restitución previsto en el artículo 12 del Convenio de La Haya que permite valorar la integración del menor en el nuevo medio a fin de rechazar la devolución, cuando ha transcurrido más de un año desde la sustracción, mientras antes del año la restitución procede de forma inmediata. Ese año no había transcurrido en el caso que se le plantea al Tribunal, sin embargo desde que se inicia el procedimiento de restitución, tres meses, hasta su finalización transcurrieron veinte meses, señalando que "cualesquiera que sean las causas y los responsables de dicha demora, no puede menoscabar el interés superior de la menor impidiendo valorar su situación actual de integración en el nuevo medio", más aún "resulta obligado que esta valoración sea decisiva". Fundamento Jurídico 10. Cfr. C. M. CAAMIÑA DOMÍNGUEZ, "El interés superior del menor: la integración en el nuevo medio", Cuadernos de Derecho Transnacional, Vol. 8, nº. 2, 2016, pp. 77-91; F. J. FORCADA MIRANDA, "El nuevo proceso español de restitución o retorno de menores en los supuestos de sustracción internacional: La decidida apuesta por la celeridad y la novedosas Circular de la Fiscalía 6/2015 (Parte II)", Bitácora Millenium DIPr., nº. 3, 2016, pp. 47-51.

84 Cfr. J. MORENO-TORRES SÁNCHEZ, La seguridad jurídica en el sistema de protección de menores español, Pamplona, 2009, p. 281. Para J. ELSTER, el rasgo común en estos temas es la incertidumbre sobre las consecuencias remotas de la decisión presente, por contraste está la certeza de que los litigios causan daños claros y inmediatos a los niños. Cfr. Juicios salomónicos..., cit., pp. 124, 146.

85 F. LÓPEZ DE OÑATE, La certeza del derecho, cit., p.40. 
que sobre ellos se tomen sea valorada por la rapidez en su ejecución, sin que la falta de colaboración de los adultos sean una justificación para que no sea así ${ }^{86}$.

Agilidad, inmediatez, evitar la rigidez o clarificar los trámites de los procedimientos que afecten a los menores, con la finalidad de no dejarlos indefensos o desprotegidos en ningún momento y no causarles perjuicios innecesarios, son parte de las garantías procesales que concretan el interés superior del menor y que constituyen algunas de las certezas del concepto.

\section{A MODO DE CONCLUSIÓN}

El tratamiento jurídico del menor ha ido evolucionando desde su consideración como destinatario de deberes naturales de protección y cuidado, a cargo de sus progenitores, a la de titulares de derechos humanos, entre los que se incluyen tanto aquellos derechos genéricos atribuidos a todos los seres humanos, como algunos derechos específicos justificados en características propias del sujeto menor.

En sintonía con la nueva perspectiva de una infancia con derechos, el bien o interés superior del menor ha sido sometido a un proceso de transformación hasta convertirse en un elemento esencial a efectos de justificar la intervención sobre su persona y sus actuaciones, estando dicho interés conformado por la garantía y efectividad de sus derechos. Es, por tanto, el ámbito de los derechos del menor el contexto en que se han de encontrar las referencias que permitan concretar el contenido de este concepto jurídico indeterminado y proporcionar un adecuado horizonte de certeza del derecho en relación a los menores.

Una certeza que, en consonancia con la nueva concepción del menor, parte de la triple dimensión del concepto: un derecho sustantivo de aplicación directa e inmediata, un principio jurídico interpretativo dirigido a resolver conflictos entre derechos, bienes e intereses diversos, y una norma de procedimiento desplegada en un amplio catálogo de derechos específicos de protección de la infancia.

\section{BIBLIOGRAFÍA}

ALEMANY, M., El paternalismo jurídico, Iustel, Madrid, 2006.

AGACINSKI, S., Política de sexos, trad. H. Subirats y M. Baiges, Taurus, Madrid, 1998.

CAAMIÑA DOMÍNGUEZ, C.M., "El interés superior del menor: la integración en el nuevo medio", Cuadernos de Derecho Transnacional, Vol. 8, n² 2, 2016, pp. 77-91.

CALVO GARCÍA, L.M., "La protección del menor y sus derechos”, Derechos y Libertades, no 1, 1993, pp. 177-199.

86 Sentencia Amanalachioai v. Rumanía, de 26 de mayo de 2009, rec. 4023/2004; Piazzi v. Italia, Lombardo v. Italia, 29 de enero de 2013; Errico v. Italia, 24 de febrero de 2009, rec. 29768/2005 (este último caso trató el retraso injustificado en la conclusión de la investigación sobre supuestos abusos que impidió restablecer la vida familiar del recurrente con su hija). 
CAMPAÑA, F.S., Interés superior del menor: técnicas de reducción de la discrecionalidad abusiva, Salamanca, 2013 (https://gredos.usal.es/jspui/bitstream/10366/124216/1/ DDP_Sim\%C3\%B3nCampa\%C3\%B1a_Farith_Tesis.pdf).

CAMPOY CERVERA, I., "Notas sobre la evolución en el reconocimiento y la protección internacional de los derechos de los Niños", Derechos y Libertades, $n^{\circ} .6$, 1998, pp. 279-327.

CAMPS, V., "Paternalismo y bien común”, DOXA, nº 5, 1988, pp. 195-202.

CAMPS MIRABET, N., "El principio del interés superior del menor: marco normativo internacional y aplicación en el Derecho", en PADIALALBÁS, A.M. y TOLDRÀ ROCA, M.D. (coords.), Estudios jurídicos sobre la protección de la infancia y la adolescencia, Tirant lo blanch, Valencia, 2007, pp. 17-40.

CILLERO BRUÑOL, M., "El interés superior del niño en el marco de la Convención Internacional sobre los derechos del niño", Justicia y Derechos del Niño, nº. 1, 1999, pp. 45-62.

DE TORRES PEREA, J.M., Interés del menor y derecho de familia. Una perspectiva multidisciplinar, Iustel, Madrid, 2009.

DWORKIN, G. "Paternalism", en SARTORIUS, R. (ed.), Paternalism, University of Minnesota Press, Minneapolis, 1993, pp. 19-34.

EEKELAAR, J., "Importance of thinking that Children have Rights", en ALSTON, Ph., PARKER S. y SEYMOUR J. (eds.), Children Rights and the Law, Clarendon Press, Oxford, 1991, pp. 221-235.

ELSTER, J., Juicios salomónicos. Las limitaciones de la racionalidad como principio de la decisión, trad. C. Gardini, Gedisa, Barcelona, 1995.

FILMER, R., "El Patriarca", en La polémica Filmer-Locke sobre la obediencia política, trad. C. Gutiérrez de Gambra, Instituto de Estudios Políticos, Madrid, 1996.

FREEMAN, M.D.A., "Talking children's rights more seriously”, en ALSTON, Ph., PARKER, S. y SEYMOUR, J. (eds.), Children Rights and the Law, Clarendon Press, Oxford, 1991, pp. 52-71.

GARZÓN VALDÉS, E., “Es éticamente justificable el paternalismo jurídico?”, DOXA, $n^{\circ} .5,1988$, pp. 155-173.

"Desde la $<$ modesta propuesta $>$ de J. Swift hasta las $<$ casas de engorde $>$. Algunas consideraciones acerca de los derechos de los niños", DOXA, $\mathrm{n}^{\circ}$. 15-16, 1994, pp. 731-743.

GONZÁlEZ AMUCHASTEGUI, J., Autonomía, dignidad y ciudadanía. Una teoría de los derechos humanos, Tirant lo blanch, Valencia, 2004.

GRANDE ARANDA, J.I., "El principio del interés superior del niño", en LÁZARO GONZÁLEZ, I. (coord.), Los menores en el Derecho español, Tecnos, Madrid, 2002, pp. 97-120.

HART, H.L.A., El concepto de Derecho, trad. G. R. Carrió, Abeledo-Perrot, Buenos Aires, 1961. 
HIERRO, L.L., "El niño y los derechos humanos”, en CAMPOY CERVERA, I. (ed.), Los derechos de los niños: perspectivas sociales, políticas, jurídicas y filosóficas, Dykinson, Madrid, 2007, pp.16-32.

"Autonomía y derechos humanos: ¿para qué se inventaron los derechos humanos?”, en ID. (coord.), Autonomía individual frente a autonomía colectiva. Derechos en conflicto, Marcial Pons, Madrid, 2014, pp. 27-52.

HUNT, L., La invención de los derechos humanos, trad. J. Beltrán Ferrer, Tusquets, Barcelona, 2009.

INIESTA DELGADO, J.J., "La cláusula de salvaguarda del interés superior del menor en la resolución de conflictos: a propósito de la inscripción registral de los nacidos en el extranjero por maternidad subrogada", en GARCÍA AMADO, J.A. (coord.), Razonar sobre derechos, Tirant lo blanch, Valencia, 2016, pp. 685-729.

KANT, I., "En torno al tópico: tal vez eso sea correcto en teoría, pero no sirve para la práctica”, en ID., Teoría y práctica, trad. M. F. Pérez López y R. Rodríguez Aramayo, Tecnos, Madrid, 1986.

KELSEN, H., ¿Qué es justicia?, trad. A. Casamiglia, Ariel, Barcelona, 1992.

LEVINAS, E., Totalidad e infinito. Ensayo sobre la exterioridad, trad. D. E. Guillot, Sígueme, Salamanca, 1987.

LIEBEL, M., "Sobre el interés de los niños y la evolución de sus facultades", Anales de la Cátedra Francisco Suárez, n 49, 2015, pp. 43-62.

LOCKE, J., Dos Ensayos sobre el gobierno civil, trad. F. Giménez Gracia, Espasa Calpe, Madrid, 1991.

Pensamientos sobre educación, trad. R. Lasaleta, Akal, Madrid, 1986.

LÓPEZ DE OÑATE, F., La certeza del Derecho, trad. S. Sentís Melendo y M. Ayerra Redin, Comares, Granada, 2007.

MacCORMICK, N., "Los derechos de los niños: una prueba de fuego para las teorías del derecho", en ID. Derecho legal y socialdemocracia. Ensayos sobre la filosofía jurídica y política, trad. L. M. González Soler, Madrid, Tecnos, 1982, pp. 129-137.

MILL, J.S., Sobre la libertad, trad. P. de Azcárate, Alianza, Madrid, 1990.

La esclavitud femenina, trad. E. Pardo Bazán, Artemisa, Madrid, 2008.

MORENO-TORRES SÁNCHEZ, J., La seguridad jurídica en el sistema de protección de menores español, Aranzadi, Pamplona, 2009.

PICONTÓ NOVALES, T., En las fronteras del Derecho. Estudio de casos y reflexiones generales, Dykinson, Madrid, 2000.

"Ruptura familiar y coparentalidad: Un análisis comparado", en Id. (ed.), La custodia compartida a debate, Dykinson, Madrid, 2012, pp. 45-76.

RAWLS, J., Teoría de la Justicia, trad. M. D. González, FCE, Madrid, 1993.

RIVERO HERNÁNDEZ, F., El interés del menor, Dykinson, Madrid, 2000.

ROCA, E., Familia y cambio social (De la “casa” a la persona), Cívitas, Madrid, 1999.

ROUSSEAU, J. J., Emilio o De la educación, trad. M. Armiño, Alianza, Madrid, 1990. 
SANTOS MORÓN, M.J., "Menores y derechos de la personalidad. La autonomía del menor", Anuario de la Facultad de Derecho de la Universidad Autónoma de Madrid, $\mathrm{n}^{\mathrm{o}} 15,2011$, pp. 62-93.

TAMAYO HAYA, S., "La custodia compartida como alternativa legal”, Revista Crítica de Derecho Inmobiliario, $\mathrm{n}^{\mathrm{o}}$. 700, 2007, pp. 667-712.

"El interés del menor como criterio de atribución de la custodia", Revista de derecho de familia: Doctrina, Jurisprudencia, Legislación, nº 41, pp. 35-79.

TRINIDAD NÚÑEZ, P., “La evolución en la protección de la vulnerabilidad por el derecho internacional de los derechos humanos", Revista Española de Relaciones Internacionales, $\mathrm{n}^{\mathrm{o}}$. 4, 2012, pp. 125-142. 